\title{
A multilevel approach to big data analysis using analytic tools and actor network theory
}

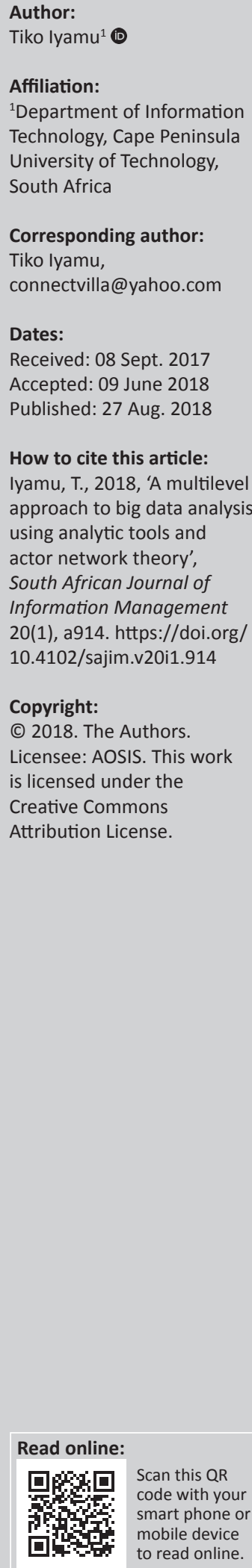

Background: Over the years, big data analytics has been statically carried out in a programmed way, which does not allow for translation of data sets from a subjective perspective. This approach affects an understanding of why and how data sets manifest themselves into various forms in the way that they do. This has a negative impact on the accuracy, redundancy and usefulness of data sets, which in turn affects the value of operations and the competitive effectiveness of an organisation. Also, the current single approach lacks a detailed examination of data sets, which big data deserve in order to improve purposefulness and usefulness.

Objective: The purpose of this study was to propose a multilevel approach to big data analysis. This includes examining how a sociotechnical theory, the actor network theory (ANT), can be complementarily used with analytic tools for big data analysis.

Method: In the study, the qualitative methods were employed from the interpretivist approach perspective.

Results: From the findings, a framework that offers big data analytics at two levels, micro(strategic) and macro- (operational) levels, was developed. Based on the framework, a model was developed, which can be used to guide the analysis of heterogeneous data sets that exist within networks.

Conclusion: The multilevel approach ensures a fully detailed analysis, which is intended to increase accuracy, reduce redundancy and put the manipulation and manifestation of data sets into perspectives for improved organisations' competitiveness.

\section{Introduction}

Big data is characterised by factors which include large volume, velocity and variety (Kitchin 2013). Ghazal et al. (2013) explains the characteristics of big data in slightly more detailed manner as follows: (1) volume, huge amount of data, which is not easy to handle and process, (2) velocity, the speed of data that flows in and out of an environment, which makes it difficult to manipulate and (3) variety, ranges and types of data, from various sources, which are not always easy to assimilate. Along the same line, Zikopoulos and Eaton (2011) describe big data as a representation of a new era in the exploration and utilisation of improved services for organisational purposes. Based on its diverse and versatile nature, big data can be applied to many areas including complex and realtime situations (Najafabadi et al. 2015).

Organisations make use of big data for various services and different reasons, which include efficiency, sustainability and competitiveness. Irrespective of size, variety and complexity, big data can be harnessed within context and relevance, towards achieving organisational goals and objectives in any area, including healthcare and social media (Mgudlwa \& Iyamu 2018). Kambatla et al. (2014) argued that big data can be simply interpreted as a set of data that are more than what an organisation can easily manage effectively and efficiently. Hence, analytics is required in order to extract value and make it easy to use for organisations' activities, including richer insight for sustainability and competiveness. Harnessing big data through analytics can increase value to organisations as it is intended to tell and present a more complete story and reality about the specific focus of an organisation (Foster 2014).

As argued by Basu (2013), the most significant breakthrough from the emergence and evolving nature of big data analytics is the technological tools, which include descriptive, prescriptive and predictive analytic approaches. However, the benefits and excitements of big data have for many years been suppressed by its challenges. According to Sharma (2015:3), 'scientists are optimistic about the big data, but express equally low confidence in the data access capabilities of 
the existing techniques'. Hence, there is need to explore alternatives, which will combine big data analytic tools with a methodological approach, at both micro- and macro-levels of analysis. I find actor network theory (ANT) a useful method of analysis, because of its focus on network heterogeneity, actors' activities and the translation of various events within each moment.

The current approach of big data analysis using analytic tools do not allow translation of data sets from a subjective perspective, which can increase the value of big data through an understanding of why and how data manifest in the way that they do (Gandomi \& Haider 2015). This has a negative impact on the accuracy, redundancy and usefulness of data sets, which affects the value of operations and the competitive effectiveness in organisations (Ghazal 2013). Also, the current single approach lacks detailed examination of huge data sets, which big data deserves in order to ensure purposefulness and usefulness (LaValle et al. 2011). Thus, only through holistic demystification of big data, values can be enhanced in harness and achievement, for improved competiveness. In the context of this article, demystification entails the multilevel analysis of big data at micro- and macro-levels. This includes defining data and human actors; examining how the actors' networks are formed and stabilised; how data sets are categorised into networks; and how to gain a better understanding of the data and actors' relationship and reproductive actions. Such analysis is intended to focus on both current and futuristic states of data set within an environment. As a result, some of the important questions in approaching any big data analytic assignment or project include the following: (1) what are the requirements? (Gandomi \& Haider 2015), (2) what are the deliverables? (Russom 2011), (3) who are the users and stakeholders? (LaValle et al. 2011) and (4) where are the stakeholders? (LaValle et al. 2011). These questions encompass heterogeneous networks of actors, which include data, processes, technologies and humans that seek to improve an approach towards finding new things. Sharma (2015) emphasises that the current state of research art in big data is still far from mature, and the scope of demystification seeks continual active research engagement in order to derive new approaches and findings.

The focus of this article was to explore big data analytic tools, examine methodological technique (ANT) for analysis and propose a multilevel approach, which can be used to improve the quality and richness of data sets through analytics. The research question was, therefore, how can big data analytics be carried out at two levels using a combination of analytic tool and theoretical framework? Thus, big data analytic tools and ANT were examined in a complementary fashion. I am not aware of any study in which ANT was complementarily used with big data analytic tools, and hence, this is considered a fresh and novel perspective.

For clarity and better understanding purposes, this article is divided into seven main sequential sections. The first section provides an introduction to the article, which includes its objective. A review of literature and related work on big data analytics and ANT are submitted in the second section. In the third section, the research approach that was employed in this study is explained. The fourth section presents the data analysis and a discussion. In the fifth section, the multilevel approach and how it can be employed for big data analysis is presented and discussed. The sixth section covers the practice of using the multilevel approach to big data analysis. A conclusion about this article is drawn in the last section.

\section{Review of related works}

The review of literature is divided into two parts, namely big data analytics and ANT. This sets the tune towards gaining an understanding of how big data analytics tools and ANT can be of complementary value in the analysis of data sets within an organisation.

\section{Big data analytics in organisations}

Big data is seen as a collection of data that has grown tremendously and become beyond the ability of commonly used software tools to capture, manage and process (Wu et al. 2014). The growth is characterised from three main perspectives: volume, variety and velocity. Data velocity is much more than a bandwidth issue; it is used for measuring the speed of data creation, streaming and aggregation (Kaisler et al. 2013). The vast use of big data makes it essential to always choose an approach that allows questioning of why things happen in the way that they do, rather than solely looking at what happened. However, big data analytics has so far been static and leans more towards a quantitative, positivist paradigm. This means that there is little or no innovation in the area of big data analytics.

Big data analytics is commonly carried out from three main perspectives as tools, which include the descriptive, the predictive and the prescriptive (Zakir, Seymour \& Berg 2015). The tools are briefly discussed as follows:

- Descriptive: focuses on the current and available data. According to Evans and Lindner (2012:2), the 'descriptive analytics can be used to examine historical data for similar products, such as the number of units sold, price at each point of sale, starting and ending inventories, and special promotions'.

- Prescriptive: reveals what actions should be taken, which usually results in the creation of rules and recommendations going forward. Evans and Lindner (2012) explained that the descriptive analytics for data analysis is mainly to gain an understanding of both the past and current performances of an organisation, in order to take informed decisions. Even though the prescriptive analytics is a valuable approach in many ways, it is rarely employed by organisations (Hazen et al. 2014).

- Predictive: makes use of big data to identify past patterns and to predict the future regards to specific needs. 
Shmueli and Koppius (2011) argued that a predictive analytic tool does not only assist in creating practically useful models but its approach also plays a significant role in building theory. Many organisations continue to explore the potential of a predictive analytic approach to their businesses, but from different perspectives (Zakir, Seymour \& Berg 2015). Some organisations make use of the approach in areas, such as sales, marketing, lead source, frequency of communications, types of communications and social media (Mgudlwa \& Iyamu 2018). Hazen, Boone, Ezell and Jones-Farmer (2014) argued that the predictive analytics describe the set of data that can be leveraged for future purposes. However, organisations use the approach for more complex forecasts. The predictive analytic approach concerns what would characterise a system that was not operating optimally (Waller \& Fawcett 2013).

Irrespective of the option of the big data analytics that is selected, there are challenges that often emanate from evidence relating to the efficacy and effectiveness of the data sets and the services that they are supposed to enable and support (Wang, Kung \& Byrd 2018). According to Katal, Wazid and Goudar (2013), one of the main challenges for both information system and technology specialists (IS and IT) and business personnel is how to filter the most important elements of big data for the purpose of service delivery. McAfee et al. (2012) highlight that the technical challenges of using big data are very real but the managerial challenges are even greater. Hence, a single approach will continually be short or problematic in finding a solution to the challenge. Otherwise, big data analytics remain a major challenge for organisations (Kaisler et al. 2013).

The underlying benefits of big data analytics, as well as the diversity of application characteristics, pose significant challenges for socio-economics in an environment (Kambatla et al. 2014). However, Gandomi and Haider (2015) suggest that by using big data analytic tools, massive volumes of semi-structured data can be mined to improve service delivery and competiveness. Thus, individual or combined analytic tools, such as the descriptive, prescriptives and predictive, are employed to guide various types of decisionmaking (Sun, Sun \& Strang 2018). However, that does not seem to solve the challenges of the holistic and in-depth extraction of useful elements from big data (Zakir et al. 2015). This includes an understanding of groups' creation, relationships between data sets, and the interaction among data within a heterogeneous network. It is within this context and basics that a multilevel approach is proposed, which complements the use of ANT as a methodological approach.

\section{Actor network theory}

The rationale for employing ANT includes its focus on the formulation of networks, relations among actors and heterogeneity of networks. Actor network theory is a sociotechnical theory that focuses on how activities that concern human and non-human actors are translated from one moment or stage to another and their relationship within heterogeneous networks. In ANT, the actor is both human and non-human, that is, 'anything that modifies a state of affairs by making a difference' (Bryson, Crosby \& Bryson 2009:71). This means that data sets and analytic tools are also actors, which are used and reused within environments (networks). According to Pollack, Costello and Sankaran (2013), ANT primarily focuses on tracing networks of associations that occur between actors, which include building an understanding of interaction. Couldry (2008) argues that ANT is a highly influential account within the sociology of science that seeks to explain social order through the networks among human and non-human actors, which include technologies and objects.

The actor network theory is increasingly used for data analysis, particularly because of its detailed descriptive and narrative emphasis as well as its ontological association. Some of the studies where ANT has been applied in recent years vary, which include Foster (2014), Horowitz (2012) and Dery et al. (2013). Pollack et al. (2013) explained that ANT allows many levels of analysis from both narrative and descriptive angles. From ANT standpoint, there is no shortage of non-human actors that can influence data, from size, velocity and variety perspectives. Especially, the fact that in ANT, it is possible and desirable to view humans and non-humans in the same analytical terms (Law 1986:258). One of the main tenets of ANT is translation (Iyamu 2015) as shown in Figure 1.

Translation involves association of heterogeneous networks within which actors are identified, interests are aligned, tasks are assigned and action plans are established (Callon 1986). Translation consists of four moments, which are intertwined and connected with one another, namely problematisation, interessement, enrolment and mobilisation (Callon 1986). Problematisation is a stage where a problem is defined based on requirements (Horowitz 2012). In ANT, a problem is not necessarily something that is broken or negative, but an innovative improvement of a situation. Based on the problematised issue, actors consciously or unconsciously show their interest. During the moment of interessement, stakeholders' interests are established, drawing from their understanding of the problematised

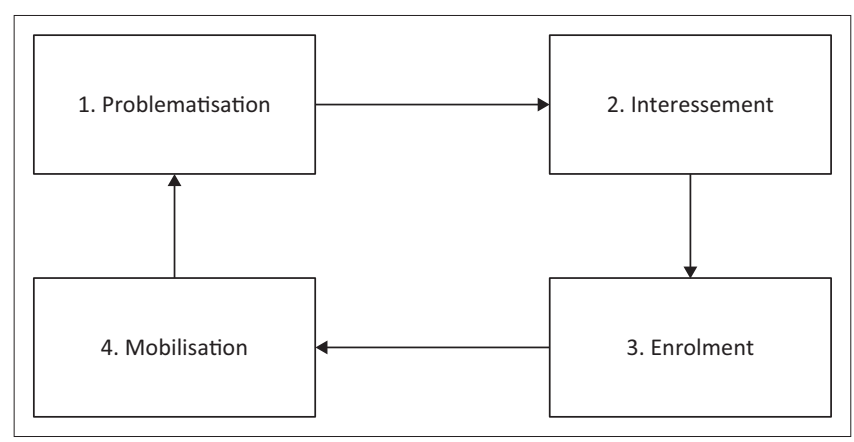

Source: Callon, M., 1986, 'Some elements of a sociology of translation: Domestication of the scallops and the fishermen of St Brieuc Bay', in J. Law (ed.), Power, action and belief: A new sociology of knowledge?, pp. 196-233, Routledge and Kegan Paul, London.

FIGURE 1: Four moments of translation. 
issue (Alcouffe, Berland \& Levant 2008). In enrolment, alliance networks are formed, and stakeholders form groupings of common interests. Mobilisation is a stage where a set of methods are used to ensure that actions are in accordance with requirements of the networks (Lee \& Oh 2006). Thus, translation helps to create groupings and relationship, through which data can be demystified and transformed for organisational purposes.

Transformation happens through moments of translation, which is based on earlier associations of actors within heterogeneous networks (Iyamu 2015). In ANT, it is only when associations have been formed or accepted, that some actors will be perceived as organising, and others as organised (Wissink 2013). This type of association helps to organise both the semi-structured and the structured data into a more useful purpose.

\section{The research approach}

Based on the objective of the study, which was to propose a multiple level approach to big data analysis, the interpretivist approach and qualitative methods were employed. The selection was also primarily based on the fact that the qualitative methods offer a rich mechanism which could lead to innovation (Venkatesh, Brown \& Bala 2013). In reality, there is currently no formula or single approach of complementary formation in the application of big data analytics (Kitchin 2013; McAfee et al. 2012; Najafabadi et al. 2015). This approach was, therefore, employed to guide a construction of reality in a social world concerning a new approach to data analytics.

The desk research approach was employed from qualitative methods' perspective through which existing works were gathered. According to Byrne (2016), the desk research approach is not necessarily the same method as a literature review; it focuses on the materials that are part of the main research. Desk research entails the collection of data through relevant publications, a process which Mai (2016) described as a time- and cost-efficient manner of conducting research, but the researcher has to be knowledgeable about research methodologies in order to avoid time and resources wasting. The approach has in recent years been increasingly used in many information systems studies. Eskerod and Huemann (2013) applied desk research in their study, in which an analytical framework was developed. Bocconi, Kampylis and Punie (2013) based their qualitative study on desk research.

A total of 45 peer-reviewed articles were gathered, of which 18 were in the area of ANT and 27 cover big data and big data analytics. The sources of the data (articles) collection include Google Scholar, ProQuest, Taylor and Francis, SAGE publications and EBSCOhost databases. The focus was on information systems. The search criteria were big data analytics, ANT for analysis and year of publication. A period of 10 years, 2008-2018, was considered to be wide enough spread to gain rich quality. This was based on Iyamu et al.'s (2016:171) explanation that the spread of years of publication is purposely to retrieve diversified historical viewpoints in terms of the consistency of the meaning that has been associated with the concepts, as well as the challenges that exist over a period of time.

The data were analysed following the interpretivist approach. An interpretivist approach provides a deep insight into understanding socially constructed reality (Andrade 2009). According to Walsham (2006:320), 'Our theories concerning reality are ways of making sense of the world, and shared meanings are a form of intersubjectivity rather than objectivity'. The interpretivist approach was, therefore, used to subjectively gain a better understanding (Hovorka \& Lee 2010) about how analytics tools can be complementarily used with ANT from a methodological perspective, in the analysis of big data.

\section{Analysis and discussion: Understanding big data analytics}

Big data analytics helps an organisation to harness its data for more purposefulness and improved ease of use towards proactive identification of new opportunities. However, there are challenges, which manifest from lack of an in-depth extraction of elements from big data. According to Gandomi and Haider (2015), some organisations focus on predictive analytics and structured data and ignore the largest component of big data, which is the unstructured part. In order to extract useful information and gain more knowledge from huge data sets, scalable analytics is required (Talia 2013). At this point, ANT was approached from an interpretivist perspective. This is to improve big data analytics from both operational and strategic perspectives. This includes the unstructured aspects of big data. The interpretivist approach begins from the position that our knowledge of reality is a social construction of human actions (Walsham 2006).

Through subjective understanding and interpretive analysis, I gathered from studies such as Sun et al. (2018), Gandomi and Haider (2015) and LaValle et al. (2011) that an understanding of big data analytics and getting substantial value for organisational purposes is more than the mere use of software tools. It first requires an understanding of the main factors, which can deterministically affect the outcome. This includes three main factors: (1) complementarity of analytics tools with method (Waller \& Fawcett 2013), (2) levels of big data analysis (Basu 2013) and (3) heterogeneity of organisational data sets (Breckels et al. 2016).

\section{Complementarity of analytics tools with method}

The ability to be effective, efficient and remain agile helps an organisation to continually improve in pursuit of service delivery. This can also help identify insights for immediate decision-making. However, from analytics perspectives, 
the quest to improve services is not always as easy as envisaged (Sun et al. 2018). This difficulty can be problematic for both the enabler (IS and IT) and the enabled (business users and managers). According to Katal et al. (2013), some of the challenges that exist for the IS and IT specialists include designing systems which would be used to handle large volumes of data from various sources and to maintain a high level of velocity, for business efficient and effective use.

The actor network theory for analysis is not new; it has been used for over three decades, primarily to interrogate social, scientific and technological networks (Horowitz 2012). The theory is scalable and flexible in that it can be combined with other approaches or techniques for analytic purposes. Thus, I consider ANT to be appropriate for gaining an understanding, formulation and stabilisation of groupings, referred to as networks of data sets, in the analytics of big data at a strategic level in an environment.

There is no single technology or approach that encompasses big data analytics. The challenges that data analytics encounter are an opportunity for complementarity. In reality, technologies and approaches can be combined to enhance the quality of analytics. Thus, complementarity of analytics tools with a method will enhance and improve the quality of analysis, for business efficiency in the use of big data. The combined use of analytics tools and a methodological approach must be carried out at two different levels, namely operational and strategic, towards achieving organisational goals and objectives.

\section{Levels of analytics}

There is a technical challenge in making use of big data. Those who know or understand what big data means do not unnecessarily understand how to extract detailed elements from it to create more values and benefits. This is to fortify and enhance the ability to work faster, stay agile and be able to identify insights for immediate decisionmaking. This could be attributed to the complexity of big data, as well as the know-how instrument for carrying out the analytic tasks. According to Najafabadi et al. (2015), in the past, strategies and solutions for data storage and retrieval were challenged by increasing massive volumes of data from different sources.

As has been established in the review, incompatibility of formats, inconsistency of data and large volumes of data are some of the obstacles that can affect big data analytics within the healthcare environment (Wang et al. 2018). Underlying this challenge, analysis has to be conducted at different levels so as to make it easier and possible, in enabling data volume, ensuring continued accuracy, and support (near) real-time processing. Another necessity for advocating for levels of analysis is because stakeholders engage with their big data from different angles, such as inter-relationship and interconnectivity. Some stakeholders are at operational level, and others are at strategic level, a divide that boost the usefulness of big data in an organisation.

The first level is 'in-tive', which consists of descriptive, predictive and prescriptive analytics tools. The output from this level is for operational use. This is a level in which more stakeholders are engaged in many organisations. At the second level, it creates networks and establishes the connections and relationships that exist among the data sets. Thereafter, it finds components and elements that were not clear beforehand, which of course must be guided by organisational requirements that are aimed to exhume values. Analysis at both levels is influenced by varied data sets in their heterogeneous state, which require an exploratory approach in order to gain more benefits.

\section{Heterogeneous data set}

As business grows, units are created for expanded functions and responsibilities. As such, organisational data are scattered across the units. Some of the data sets are, therefore, duplicated over a period of time. As a result, the data are sometimes interoperated for the purposes of service delivery, which is often a challenging task to undertake. This, therefore, requires heterogeneity in its analytics. This is to be holistic and uncover hidden entities across the data sets.

The size of big data is increased by the heterogeneity of data sets. This often poses major challenges in an attempt to gain an understanding of available data and how it can be analysed. According to Breckels et al. (2016), meaningful integration of heterogeneous data is a major challenge. A detailed approach that is split into levels is, therefore, needed in order to accommodate the heterogeneity of data sets, from various sources (Pincus \& Musen 2003).

\section{Multilevel approach to big data through analytics and actor network theory}

A multilevel approach is necessary to bring about innovation, which combines operational (macro) and strategic (micro) levels of big data analysis in their epistemological and ontological perspectives. The micro-level defines and establishes the networks formation and interaction, whereas the macro level is the current approach of big data analytics. Wright and Boswell (2002) emphasise the importance of integrating both micro- and macro-levels of analyses. In Evans and Lindner's (2012) assessment, the tools that are used in descriptive, predictive and prescriptive analytics are different; however, some software applications can combine the three approaches, which takes an epistemological stance. According to Bleakley (2012), ANT is not primarily interested in epistemologies, but in ontologies, which include how meanings are generated within networks and how the different networks are formulated and significantly shape activities. Fenwick (2010) argues that networks of prescription 
and networks of negotiation co-exist from ontological perspective, to form the same standards of activities.

A multilevel approach for big data analysis which was developed from this study is presented as Figure 2. The approach consists of operational and strategic levels of analysis aimed at the demystification of data sets, using business requirements. The divide between the operational and strategic levels of analysis, using both analytic tools and a method, is critically significant in big data analytics, from depth and details perspectives, in achieving business requirements.

The multilevel approach is a combination of micro- and macro-levels, a process for the transformation of big data in an organisation. The approach is intended to increase the benefits of big data analysis in an organisation. Also, the approach unpacks complex and huge data sets into perspectives and relevance at the micro-level, which is strategic. At the operational level, which is the macro-level, the approach reduces complex data sets into actionable artefacts, for more effective and accurate decision-making. The micro- and macro-transformative process is primarily for the improved demystification of big data at both strategic and operational levels, to enhance business capability and promote competitiveness.

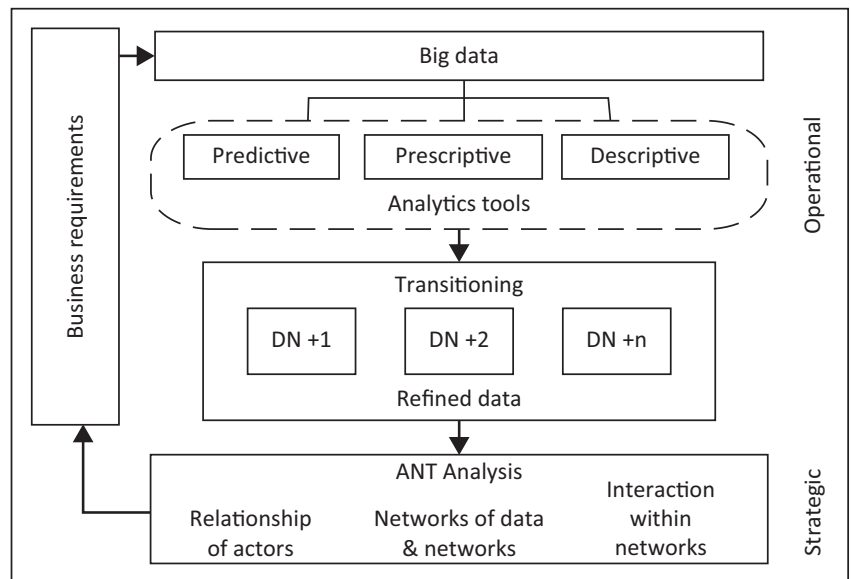

FIGURE 2: Multilevel analysis of big data.

As shown in Figure 2, the multilevel approach is primarily to gain new insights from big data, for decision-making at both operational and strategic levels in an organisation. This is intended to provide more detailed information about activities concerning data sets, in improving service delivery. The main components of the multilevel approach are discussed as follows:

\section{Business requirements}

Big data analytics is considered to be a relatively new and emerging field, which requires integration of state-of-theart computational and statistical techniques that enable and allow extraction of business value from a volume of diverse sets of data. The data sets are gathered from different sources by using various techniques. Initially, the data sets are considered raw and make little or no sense, which the business requirements help demystify towards purposeful use.

\section{Big data}

Big data analytics is the science of examining raw data with the purpose of drawing conclusions about accumulated information over a period of time. Big data analytics is used in many industries to allow organisations to make better business decisions through descriptive, prescriptive or predictive approaches. Wang et al. (2018) explained that the future approaches have the capability to assess model for futuristic tenacities. Also, the big data analytics is a form of science that can be used to verify or disprove existing models or theories. Big data analytics is distinguished from data mining based on scope, purpose and focus of the analysis, which makes it more complex and difficult if applied alone.

In big data analytics, using tools such as the descriptive, prescriptive and predictive perspectives, traces of actions and response are fundamental. The actor network theory complements at this point, in that it allows and enables traces of association, re-association and reassembly of actors and their reproductive actions within networks (environment). According to Bryson et al. (2009), through ANT, associations can be traced by allowing actors to reassemble in a social network.

\section{Operational level}

At operational level, different moments and their translation influence the technical and non-technical situations of big data. The situations can be categorised into volume, variety and velocity of big data in any environment, using different analytics tools. The predictive approach is an analysis of likely scenarios of what might happen. The deliverables are usually a predictive forecast. According to Shmueli and Koppius (2011), predictive analytics can focus on predictors (human actors) and methods (non-human) that reproduce relatively refined data and a transparent model. Waller and Fawcett (2013) explained that the predictive analytics approach attempts to quickly and inexpensively approximate relationships between variables, subjects or objects. According to Basu (2013), for a prescriptive analytics technology to be transformative, it must be able to process hybrid data. Descriptive analytics is the approach that focuses on uncovering patterns that offer insight into an organisation. A simple example of descriptive analytics would be assessing credit risk and the categorisation of customers by their likely product preferences and sales cycle.

\section{Strategic level}

In complement with analytics tools, ANT as a method is appropriate at the strategic level of analysis of big data. This is mainly because of its specific focuses as explained by Feldman and Pentland (2008:306) that ANT has specific 
focuses on the following: (1) performances, (2) associations or connections with non-human elements or aspects of the situation and (3) account for how the ostensive aspects of any set of associations are produced, become stabilised and legitimised, or change, through strengthening or weakening associations, respectively. As a method, Latour (2005) argues that ANT strength can be drawn from groupings as defined, such as: how actions manifest, and an understanding of facts versus 'matters of concern'.

ANT looks at many different ways of identifying groups, because actors themselves identify groups in a variety of ways. Gao (2005) argues that ANT examines the various motivations and reproductive actions of actors within requirements and, therefore, it is different from other sociotechnical theories.

In summary, the micro-level facilitates the strategic outcomes from the analytic angle, whereas the macro-level guides the splits of data for operational constructs and demystifications. At the micro-level, the first level of analysis clarifies the ontologies of the big data and its entities within specific environments. The macro-level is epistemologies, the second level of analysis to understanding subjects, objects, devices, contexts and cultural factors in big data. At this level, I propose the application of moment of translation from the perspective of ANT as shown in Figure 1.

\section{Understanding the impact of multilevel approach}

In an understanding of the impact of the multilevel approach, the role of ANT is reiterated. Data sets from big data analytics can be less stable without categorisation of their networks. Data as actors can be classified through the moments of translation from the perspective of ANT. Iyamu and Roode (2010) explained that the idea of problematisation is mainly to foster relationships and allocate and reallocate facilities among actors. The facilities are dictated by specific requirements within which big data analytics is carried out. Through interessement, an actor takes a set of actions to impose and stabilise the identity of other actors in the same network. Dery et al. (2013) suggest that interessement helps to create the conditions for the third moment of actornetwork formation, enrolment, which involves the definition of actors' roles in the network. According to Unnithan et al. (2013), enrolment facilitates a situation where actors accept the roles that have been defined for them in their various networks. In summary, Fenwick (2011) states that the problem that is divided into spaces and actions in accordance with issues of relationship, roles and difference becomes connected and mobilised into networks.

Based on the multilevel approach for big data analysis, three factors standout. This includes networks, actors and relationship, and big data analytics as shown in Figure 3. The factors are discussed from the perspective of the multilevel approach.

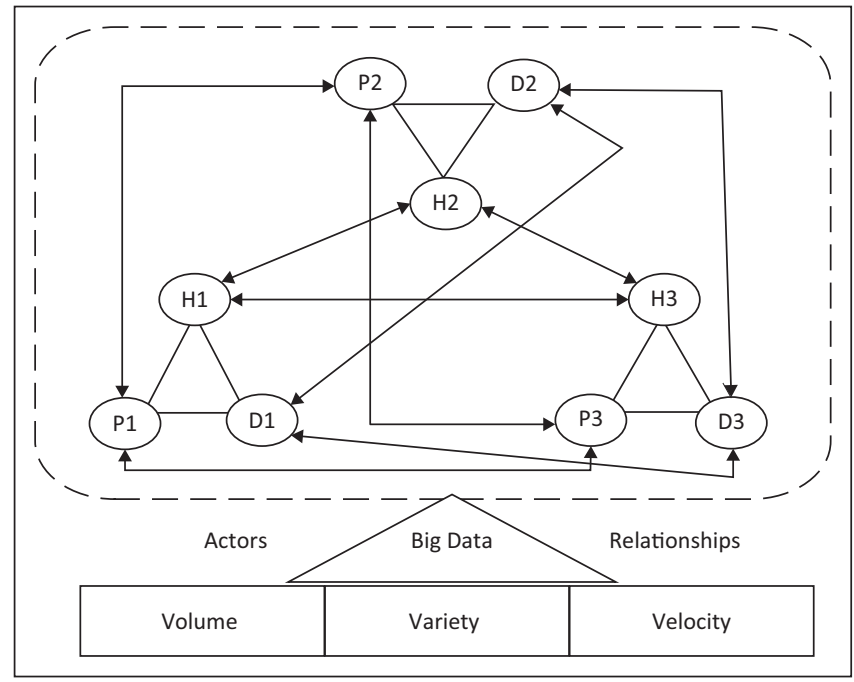

FIGURE 3: Heterogeneity of big data.

\section{Networks}

Figure 3 presents the heterogeneous networks within which big data can be demystified, towards achieving improved services for competitiveness and sustainability. The multilevel approach of analysis unveils the signification of actors' relationship within networks. Through this approach, big data is reduced to small data, making each data set more purposeful, meaningful and useful. Also, each data set becomes easier to associate with other objects and subjects, such as sale, marketing and health conditions.

\section{Actors and relationship}

As shown in Figure 3, the impact of multilevel analytics is threefold, which enhances the understanding and the usefulness of big data in an organisation. Firstly, the scope of the data must be understood, which the analytic tools focus on. Only then, it can be effectively and efficiently used to communicate and interact among actors, for the good of an organisation, in improving services. Secondly, the associated factors, which are of a technical and non-technical nature, must be clearly defined, by using moments of translation to examine how networks are formed and stabilised. This helps to streamline and clarify the relationship among the actors, which guides the ease of big data use for organisational purposes. Finally, the business requirements act as a catalyst to the existence of big data in an organisation. The three components are tightly related and connected in the context of the multilevel big data analysis concept. Therefore, three components cannot be viewed or treated in isolation if big data analysis is to be understood and employed within environments.

\section{Big data analytics}

The analytic tools sort through huge data sets using sophisticated software to identify undiscovered patterns and establish hidden relationships. Data analytics focus on inference, the process of deriving a conclusion based solely on what is already known by the analyst or researcher. 
This enables the process of examining and gaining an understanding of data sets in order to uncover and extract trends and patterns, unfamiliar correlations, customer preferences and other useful business information. According to Russom (2011), data analytic tools are used to create analytic models or fashion complex queries. The process requires the use of techniques, such as text analytics, machine learning, predictive analytics, data mining, statistical methods and natural language processing, for businesses. Zaslavsky, Perera and Georgakopoulos (2013) argue that the concept of big data is defined on the basis of its main characteristics, which include volume, variety and velocity. In different ways and levels, volume, variety and velocity expand the capability to enhance services.

Through the use of ANT's moments of translation for analysis, the epistemology of big data can be better understood through a heterogeneity of networks. The process facilitates where a new network starts to operate in a target (requirements-based)-orientated approach to implement the solution proposed. This can lead to the strengthening and stabilisation of big data purposeful usage within networks. Fenwick (2010) suggests that the conclusion drawn from the analysis helps to assess and examine the usefulness of big data within an environment (network).

\section{Conclusion}

Big data analysis can be carried out by using the multilevel approach, a complementarity of ANT and analytics tools, as proposed in this article. In the ANT's moments of translation, I find a useful lens in understanding and examining the analytics of big data. Through the use of the translation process at a strategic level of analysis, it can be easier to trace how varieties of data accelerate in their various sizes, in accordance with requirements. By drawing on the four moments of translation from ANT, big data is analysed and fortified for strategic use and purposes.

The multilevel level approach adds more value to big data analysis from a more theoretical, practical and methodological views, which can benefit for both business and academic domains. Practically and methodologically, businesses will realistically understand the roles and influences of human and data networks while applying analytics tools. This includes the ability and usefulness of splitting the analysis into operational and strategic levels. To the academic domain, the article contributes from both theoretical and methodological perspectives, in that it brings rigour into exploring and understanding big data without losing both the human and non-human factors. In addition, this article contributes to existing literature, but from a different angle.

However, the study lays a foundation for future studies and triggers further discourse in the area of multilevel analysis of big data. Some of the areas of further research include security within the networks, particularly in the healthcare and financial sectors. Also, further studies to integrate ANT with big data analytics tools into one entity will be of interest to both organisations and academics.

\section{Acknowledgements Competing interests}

The author declares that he has no financial or personal relationships that may have inappropriately influenced him in writing this article.

\section{References}

Alcouffe, S., Berland, N. \& Levant, Y., 2008, 'Actor-networks and the diffusion of management accounting innovations: A comparative study', Management Accounting Research 19(1), 1-17. https://doi.org/10.1016/j.mar.2007.04.001

Andrade, A.D., 2009, 'Interpretive research aiming at theory building: Adopting and adapting the case study design', The Qualitative Report 14(1), 42-60.

Basu, A.T.A.N.U., 2013, 'Five pillars of prescriptive analytics success', Analytics magazine, pp. 8-12, viewed 16 March 2017, from http://www.informs.org

Bleakley, A., 2012, 'The proof is in the pudding: Putting actor-network-theory to work in medical education', Medical Teacher 34(6), 462-467. https://doi.org/10.3109/ 0142159X.2012.671977

Bocconi, S., Kampylis, P. \& Punie, Y., 2013, 'Framing ICT-enabled innovation for learning: The case of one-to-one learning initiatives in Europe', European Journa of Education 48(1), 113-130. https://doi.org/10.1111/ejed.12021

Breckels, L.M., Holden, S.B., Wojnar, D., Mulvey, C.M., Christoforou, A., Groen, A. et al., 2016, 'Learning from heterogeneous data sources: An application in spatial proteomics', PLoS Computational Biology 12(5), e1004920. https://doi. org/10.1371/journal.pcbi.1004920

Bryson, J.M., Crosby, B.C. \& Bryson, J.K., 2009, 'Understanding strategic planning and the formulation and implementation of strategic plans as a way of knowing: The contributions of actor-network theory', International Public Management Journa 12(2), 172-207. https://doi.org/10.1080/10967490902873473

Byrne, D., 2016, 'How does the literature review differ from doing desk research?', Project Planner, viewed 23 February 2017, from http://methods.sagepub.com/ base/download/StageSection/488

Callon, M., 1986, 'Some elements of a sociology of translation: Domestication of the scallops and the fishermen of St Brieuc Bay', in J. Law (ed.), Power, action and belief: A new sociology of knowledge?, pp. 196-233, Routledge and Kegan Paul, belief: $A$
London.

Couldry, N., 2008, 'Actor network theory and media: Do they connect and on what terms?', in A. Hepp, F. Krotz, S. Moores \& C. Winter (eds.) Connectivity, networks and flows: Conceptualizing contemporary communications, pp. 93-110, Hampton Press, Inc., Cresskill, NJ.

Dery, K., Hall, R., Wailes, N. \& Wiblen, S., 2013, 'Lost in translation? An actor-network approach to HRIS implementation', The Journal of Strategic Information Systems 22(3), 225-237. https://doi.org/10.1016/j.jsis.2013.03.002

Eskerod, P. \& Huemann, M., 2013, 'Sustainable development and project stakeholder management: What standards say', International Journal of Managing Projects in Business 6(1), 36-50. https://doi.org/10.1108/17538371311291017

Evans, J.R. \& Lindner, C.H., 2012, 'Business analytics: The next frontier for decision sciences', Decision Line 43(2), 4-6.

Feldman, M.S. \& Pentland, B.T., 2008, 'Routine dynamics', in D. Barry \& $\mathrm{H}$. Hansen (eds.), The Sage handbook of new approaches in management and organization, pp. 302-317, Sage, Thousand Oaks, CA

Fenwick, T., 2011, 'Reading educational reform with actor network theory: Fluid spaces, otherings, and ambivalences', Educational Philosophy and Theory 43(s1), 114-134. https://doi.org/10.1111/j.1469-5812.2009.00609.x

Fenwick, T.J., 2010, '(un) Doing standards in education with actor network theory', Journal of Education Policy 25(2), 117-133.

Foster, L.A., 2014, 'Critical cultural translation: A socio-legal framework for regulatory orders', Indiana Journal of Global Legal Studies 21(1), 79-105. https://doi. org/10.2979/indjglolegstu.21.1.79

Gandomi, A. \& Haider, M., 2015, 'Beyond the hype: Big data concepts, methods, and analytics', International Journal of Information Management 35(2), 137-144. https://doi.org/10.1016/j.ijinfomgt.2014.10.007

Gao, P., 2005, 'Using actor network theory to analyse strategy formulation', Information Systems Journal 15(3), 255-275. https://doi.org/10.1111/j.1365 2575.2005.00197.x

Ghazal, A., Rabl, T., Hu, M., Raab, F., Poess, M., Crolotte, A. \& Jacobsen, H.A., 2013 'BigBench: Towards an industry standard benchmark for big data analytics', in Proceedings of the 2013 ACM SIGMOD International Conference on Management of Data, ACM, New York, June 22-27, 2013, pp. 1197-1208.

Hazen, B.T., Boone, C.A., Ezell, J.D. \& Jones-Farmer, L.A., 2014, 'Data quality for data science, predictive analytics, and big data in supply chain management: An introduction to the problem and suggestions for research and applications', International Journal of Production Economics 154, 72-80. https://doi. org/10.1016/j.ijpe.2014.04.018 
Hovorka, D.S. \& Lee, A.S., 2010, 'Reframing interpretivism and positivism as understanding and explanation: Consequences for Information Systems Research', understanding and explanation: Consequences for Information Systems Research',
in International Conference on Information System, ICIS, Saint Louis, MO, December 12-15, $188 \mathrm{p}$.

Horowitz, L.S., 2012, 'Translation alignment: Actor network theory, resistance, and the power dynamics of alliance in New Caledonia', Antipode 44(3), 806-827. https://doi.org/10.1111/j.1467-8330.2011.00926.x

Iyamu, T., Nehemia-Maletzky, M. \& Shaanika, I., 2016, 'The overlapping nature of Business Analysis and Business Architecture: What we need to know', Electronic Journal of Information Systems Evaluation 19(3), 169-179.

Iyamu, T., 2015, Application of underpinning theories in information systems, Heidelberg Press, Australia, Victoria.

Iyamu, T. \& Roode, D., 2010, 'The use of structuration theory and actor network theory for analysis: Case study of a financial institution', International Journal of Actor-Network Theory and Technological Innovation 2(1), 1-17. https://doi. org/10.4018/jantti.2010071601

Kaisler, S., Armour, F., Espinosa, J.A. \& Money, W., 2013, 'Big data: Issues and challenges moving forward', in System sciences (HICSS), 2013 46th Hawai international conference on, IEEE, pp. 995-1004.

Kambatla, K., Kollias, G., Kumar, V. \& Grama, A., 2014, 'Trends in big data analytics', Journal of Parallel and Distributed Computing 74(7), 2561-2573. https://doi. org/10.1016/j.jpdc.2014.01.003

Katal, A., Wazid, M. \& Goudar, R.H., 2013, 'Big data: Issues, challenges, tools and good practices', in Contemporary Computing (IC3), 2013 Sixth International Conference on, IEEE, pp. 404-409.

Kitchin, R., 2013, 'Big data and human geography: Opportunities, challenges and risks', Dialogues in human geography 3(3), 262-267. https://doi. org $/ 10.1177 / 2043820613513388$

Latour, B., 2005, Reassembling the social, Oxford University Press, Sage, Thousand Oaks, CA

LaValle, S., Lesser, E., Shockley, R., Hopkins, M.S. \& Kruschwitz, N., 2011, 'Big data, analytics and the path from insights to value', MIT Sloan Management Review 52(2), 21.

Law, J., 1986, 'On the methods of long-distance control: Vessels, navigation and the Portuguese route to India', in J. Law (ed.), Power, action, and belief: A new sociology of knowledge, pp. 234-263 Routledge \& Kegan Paul, London.

Lee, H. \& Oh, S., 2006, 'A standards war waged by a developing country: Understanding international standard setting from the actor-network perspective', The Journal of Strategic Information Systems 15(3), 177-195. https://doi.org/10.1016/j.jsis.2005. 10.002

Mai, H., 2016, Business possibilities of Finnish pulp sector in Vietnamese market, viewed 15 March 2017, from https://www.theseus.fi/bitstream/handle/10024/108320/ Huong_Mai.pdf?sequence=1\&isAllowed $=y$

McAfee, A., Brynjolfsson, E., Davenport, T.H., Patil, D.J. \& Barton, D., 2012, 'Big data: The management revolution', Harvard Business Review 90(10), 60-68.

Mgudlwa, S. \& Iyamu, T., 2018, 'Integration of social media with healthcare big data for improved service delivery', South African Journal of Information Management 20(1), a894. https://doi.org/10.4102/sajim.v20i1.894

Najafabadi, M.M., Villanustre, F., Khoshgoftaar, T.M., Seliya, N., Wald, R. \& Muharemagic, E., 2015, 'Deep learning applications and challenges in big data analytics', Journal of Big Data 2(1), 1. https://doi.org/10.1186/s40537-014-0007-7
Pincus, Z. \& Musen, M.A., 2003, 'Contextualizing heterogeneous data for integration and inference', in AMIA Annual Symposium Proceedings, vol. 2003, American Medical Informatics Association, Musen, MA.

Pollack, J., Costello, K. \& Sankaran, S., 2013, 'Applying actor-network theory as a sensemaking framework for complex organisational change programs', International Journal of Project Management 31(8), 1118-1128. https://doi. org/10.1016/j.ijproman.2012.12.007

Russom, P., 2011, 'Big data analytics', TDWI best practices report, fourth quarter, pp. 1-35.

Sharma, S., 2015, An extended classification and comparison of nosql big data models. arXiv preprint arXiv:1509.08035.

Shmueli, G. \& Koppius, O.R., 2011, 'Predictive analytics in information systems research', MIS Quarterly 35(3), 553-572. https://doi.org/10.2307/23042796

Sun, Z., Sun, L. \& Strang, K., 2018, 'Big data analytics services for enhancing business intelligence', Journal of Computer Information Systems 58(2), 162-169. https:// doi.org/10.1080/08874417.2016.1220239

Talia, D., 2013, 'Toward cloud-based big-data analytics', IEEE Computer Science 46(5), 98-101.

Unnithan, C., Nguyen, L., Fraunholz, B. \& Tatnall, A., 2013, 'RFID translation into Australian hospitals: An exploration through Actor-Network Theoretical (ANT) lens', in Information Society (i-Society), 2013 International Conference on, IEEE, Toronto, ON , Canada, June 24-26, pp. 85-90.

Venkatesh, V., Brown, S. A. \& Bala, H., 2013, 'Bridging the qualitativequantitative divide: Guidelines for conducting mixed methods research in information systems', MIS Quarterly 37(1), 21-54. https://doi.org/10.25300/ $\mathrm{MISQ} / 2013 / 37.1 .02$

Waller, M.A. \& Fawcett, S.E., 2013, 'Data science, predictive analytics, and big data: A revolution that will transform supply chain design and management', Journal of Business Logistics 34(2), 77-84. https://doi.org/10.1111/jbl.12010

Walsham, G., 2006, 'Doing interpretive research', European Journal of Information Systems 15(3), 320-330. https://doi.org/10.1057/palgrave.ejis.3000589

Wang, Y., Kung, L. \& Byrd, T.A., 2018, 'Big data analytics: Understanding its capabilities and potential benefits for healthcare organizations', Technological Forecasting and Social Change 126, 3-13. https://doi.org/10.1016/j.techfore.2015.12.019

Wissink, B., 2013, 'Enclave urbanism in Mumbai: An actor-network-theory analysis of urban (dis) connection', Geoforum 47, 1-11. https://doi.org/10.1016/j. geoforum.2013.02.009

Wright, P.M. \& Boswell, W.R., 2002, 'Desegregating HRM: A review and synthesis of micro and macro human resource management research', Journal of Management 28(3), 247-276. https://doi.org/10.1177/014920630202800302

Wu, X., Zhu, X., Wu, G.Q. \& Ding, W., 2014, 'Data mining with big data', IEEE Transactions on knowledge and data engineering 26(1), 97-107. https://doi. org/10.1109/TKDE.2013.109

Zakir, J., Seymour, T. \& Berg, K., 2015, 'Big data analytics', Issue in Information Systems 16(2), 81-90.

Zaslavsky, A., Perera, C. \& Georgakopoulos, D., 2013, Sensing as a service and big data, arXiv preprint arXiv:1301.0159.

Zikopoulos, P. \& Eaton, C., 2011, Understanding big data: Analytics for enterprise class hadoop and streaming data, McGraw-Hill, Osborne Media, New York. 